\title{
O efeito 2666 e o modelo fractal ${ }^{1}$
}

\author{
Marilina Casas Casals ${ }^{2}$
}

\section{Tradução: Ana Isabel Guimarães Borges ${ }^{3}$}

Resumo: Este artigo parte de um exame da repercussão, do sucesso e das circunstâncias especiais da escrita e publicação internacional do romance para especificar o que está sendo chamado de efeito 2666. Procede-se assim para focalizar a análise dos paratextos e incipit (parágrafos iniciais) das diferentes partes de 2666 no horizonte do fractal e da fractalidade, segundo Benoit Mandelbrot e Wolfgang Welsch, e das temáticas da busca, da representação do horror sem mediações e da autoria. Com esta última, toca-se na tentativa de superação dos limites do romance como gênero em 2666, relacionada com a questão da Global Novel. Palavras chave: Roberto Bolaño. 2666. Fractal-fractalidade. Autoria. Global Novel.

Teste trabalho, proponho uma análise de 2666 a partir do estudo significativos: por um lado, as repercussões e o sucesso suscitados pelo aparecimento desse romance; e, pelo outro, as circunstâncias especiais sob as quais ele é escrito e publicado. Partindo dessa demarcação, passaremos, em segundo lugar, à análise do romance: focalizaremos os paratextos, no sentido dado ao termo por Gérard Genette; depois apresentaremos as diferentes "partes" do romance e proporemos uma análise das mesmas tendo em vista problemáticas em comum que remetem ao horizonte do fractal e da fractalidade, válido para a poesia e a narrativa de Roberto

1 Este artigo foi publicado pela primeira vez em espanhol, na revista Letra Anexa no. 1, da Universidade Tecnológica de Pereira, Colômbia, novembro de 2015, p. 21-34. Sai aqui, no Cadernos de Letras, pela primeira vez em português, em tradução de Ana Isabel Guimarães Borges.

2 Marilina Casas Casals é professora de Língua Castelhana e História na Universidade de Tübingen. Possui Licenciatura em História, Faculdade de Filosofia e Letras, Universidade de Buenos Aires (2003-2010).

3 Professora Adjunta de Literatura Espanhola na Universidade Federal Fluminense e tradutora literária. Graduada em Ciências Sociais pela Universidade de Costa Rica e Doutora em Letras Neolatinas (Estudos Literários, Literaturas Hispânicas) pela Universidade Federal do Rio de Janeiro. 
Bolaño, no sentido matemático desse termo: propriedade de figuras espaciais em múltiplos elementos que mantêm sua forma, sem importar o ângulo de visão a partir do qual elas são consideradas. ${ }^{4}$

A pergunta de fundo que guia este percurso através de 2666 por algumas das suas múltiplas entradas é a suspeita de que, por trás da obra, há um projeto muito mais ambicioso e complexo, relacionado com superar e questionar as fronteiras do romance como gênero literário e da procura, até então conhecida, realizada através dele.

\section{Recepção de 2666}

Consideradas as dimensões da obra, um dos primeiros aspectos que salta aos olhos de qualquer estudioso da obra de Bolaño ao iniciar uma pesquisa sobre 2666 é o sucesso da recepção desse romance a nível internacional. Esse aspecto não é de pequena importância e e por isso foi um dos pontos de partida escolhidos para iniciar a presente pesquisa.

As reiteradas reedições de 2666 pela Editorial Anagrama constituem um primeiro sinal do sucesso alcançado no mercado de língua espanhola. Consideremos que, no ano 2009, a editora já estava festejando sua décima edição. Mas esse público será apenas um dos vários que acolherão o romance: o seguinte foco do "fenômeno Bolaño" iniciado com 2666 provém, sem dúvida, do mundo anglo-saxão. Após a sua publicação em inglês em 2008, o romance 2666 encontra uma recepção de incontestável sucesso no interior do mercado de leitores de língua inglesa (especialmente nos Estados Unidos), apesar de tratar-se de um livro de mais de mil páginas. Contando com um importante suporte publicitário, proveniente dos mais diversos

4 Segundo o artigo de Dunia Gras, "Roberto Bolaño y la obra total". Celina Manzoni, Dunia Gras, Roberto Brodsky (eds.). Jornadas homenaje a Roberto Bolaño (1953-2003). Barcelona: ICCI Casa Amèrica a Catalunya, 2005, 5173, o escritor teria usado esse termo, apesar de que Gras não precisa a proveniência nem o uso por Bolaño. Sobre o interesse pela dimensão do fractal desde as etapas iniciais do debate sobre o pós-modernismo, ver Wolfgang Welsch, Unsere postmoderne Moderne. Weinheim: VCH, Acta Humaniora, 1987, 77-188. 
espaços do espectro midiático, torna-se possível o fato, tão estranho nesse país, de um livro traduzido alcançar um lugar privilegiado nos principais rankings de vendas. 2666 não apenas será recomendado e divulgado pelo New York Times e o The New York Review of Books, mas também conseguirá chegar a um público mais amplo através da publicidade que outro meio particular lhe destina. Trata-se de Oprah Winfrey, um fenômeno midiático nos Estados Unidos, em cuja revista “O” será publicada uma das primeiras críticas do romance, a de Vince Passaro, "Lines in the Sand. A Literary Supernova's Powerfull Novel of Live and Death on the Mexican Border". ${ }^{5}$

Com a exposição de Frida Kahlo em Nova Iorque, no começo dos anos 1990, criou-se o termo Fridomania. O sucesso de 2666 no mercado de leitores de língua inglesa constitui o início da chamada "Bolañomania", termo cunhado por um jornalista da publicação inglesa The Economist em novembro de 2008, ao ser publicada a tradução ("Bolaño-man[í]a. Hymn to a dead chilean"). Desde então, essa palavra tem sido usada repetidamente para dar conta do sucesso do labor literário de Roberto Bolaño com a publicação de 2666. Por ocasião da tradução e publicação do romance para o tcheco, um jornalista de língua espanhola definiu "Bolañomania" do seguinte modo:

La "bolañomanía" es un fenómeno en boga en todo el mundo en la actualidad. Tiene relación con el fervor casi religioso con el que es recibida la obra del fallecido escritor chileno Roberto Bolaño allá donde se edita. Si hace poco su novela "Los Detectives Salvajes" fue presentada en su traducción al chino mandarín, la lengua más hablada a nivel mundial, y la semana pasada su otra obra maestra, " 2666 ", se publicó en Portugal, ahora es el turno de la República

5 Ver Rodríguez, M. “Bolañomanía sin tildes” (2008). 
Ainda que já esteja subentendido, o fato de referir-se a 2666 como "o" romance de Bolaño tanto na fala cotidiana, na imprensa, quanto no mundo acadêmico - um olhar às circunstâncias sob as quais o romance foi escrito e, depois da morte anunciada de Bolaño, publicado -, contribui para tornar mais complexo e matizar esse aspecto. Dessa forma, não serão apenas as circunstâncias sob as quais Bolaño trabalha em seu romance, de doença e possível morte mas também sua intenção, a de deixar assegurado o futuro econômico da família, que serão os rasgos em torno do surgimento de 2666. Esses aspectos fizeram com que Bolaño concebesse cada parte ou capítulo do romance como um livro em si, destinado a ser publicado separadamente. Após sua morte, entretanto, a editora e os herdeiros do autor acharam mais conveniente publicar os diferentes livros em um único volume. Evidentemente, essa decisão, de conhecedores do mercado, não foi nem um pouco errada ${ }^{7}$.

Por isso permitiremos que "a" grande obra deixe de ser por um momento o que é para considerar as circunstâncias de sua escrita e de seu surgimento. Isso é importante para entender que o que hoje nos chega como produto da "Bolañomania" (artigos de jornais, novas edições do romance, artigos acadêmicos) tem uma história anterior que precisa ser considerada.

\section{Alguns rastros no deserto: paratextos e intertextualidade em}

\section{6}

6 'A 'bolañomania' é moda, atualmente, no mundo inteiro. Tem relação com o fervor quase religioso com o qual se recebe a obra do falecido escritor chileno Roberto Bolaño onde quer que se edite. Se há pouco seu romance Los detectives salvajes foi traduzido ao mandarim, a língua mais falada mundialmente, e na semana passada sua outra obra prima, 2666, foi publicada em Portugal, agora é a vez da República Tcheca."

7 Ver a "Nota dos herdeiros do autor" em 2666. 
Feitas essas observações sobre o surgimento e a recepção do romance, o que se propõe na continuação é focalizar alguns paratextos de 2666, com a finalidade de concentrar a atenção em alguns elementos e sinais do autor, que marcam desde o início linhas fundamentais para percorrer significativamente o texto. Há também aqui referências intertextuais a obras anteriores de Bolaño, fundamentais para a submersão no romance.

Que sugestão para o leitor está por trás de um título tão incomum como 2666? Trata-se, à primeira vista, de uma cifra que, consideradas as características da/s história/s narrada/s no romance e do discurso narrativo, bem poderia representar o número de uma longa série, como também uma data de um futuro distante e infinito.

Ainda que 2666 possa estar evocando particularmente um número no interior de uma longa série e, visto de perto, a série da longa lista de mulheres assassinadas no deserto de Sonora, essa é uma hipótese que não pode ser confirmada. Em "A parte dos crimes", na qual são narrados de maneira especialmente sistemática e repetitiva os descobrimentos dos corpos, estes não têm sequer número. Pelo contrário, o texto se refere a eles como "La siguiente muerta", tratando-se de uma série anônima (BOLAÑO, 2009, p. 627).

Se em vez disso considerarmos, em especial, as vozes que narram a história de 2666, é mais provável que o título esteja evocando uma data no futuro, quando a história é narrada. Uma análise da forma de narração que lemos nos inícios de cada "parte" confirma essa tese:

A parte dos críticos: "La primera vez que Jean-Claude Pelletier leyó a Benno von Archimboldi fue en la navidad de 1980, en París en donde cursaba estudios universitarios de literatura alemana, a la edad de 
diecinueve años." (BOLAÑO, 2009, p. 13)

A parte de Amalfitano: "No sé qué he venido a hacer a Santa Teresa, se dijo Amalfitano al cabo de estar viviendo en la ciudad. ¿No lo sabes? ¿Realmente no lo sabes?, se preguntó. Verdaderamente no lo sé, se dijo a sí mismo, y no pudo ser más elocuente. ${ }^{9 \prime}$ (BOLAÑO, 2009, p. 209)

A parte de Fate: “¿Cuándo empezó todo?, pensó “En qué momento me sumergí? (...) ¿ ¿realmente quería salir? ¿Realmente quería dejarlo todo atrás? Y también pensó: el dolor ya no importa. Y también: tal vez todo empezó con la muerte de mi madre. ${ }^{10 "}$ (BOLAÑO, 2009, p. 293).

A parte dos crimes: "La muerta apareció en un pequeño descampado en la colonia Flores. Vestía camiseta blanca de manga larga y falda de color amarillo hasta las rodillas, de una talla superior. ${ }^{11 "}$ (BOLAÑO, 2009, p. 441)

A parte de Archimboldi: "Su madre era tuerta. Tenía el pelo muy rubio y era tuerta. Su ssojo bueno era apacible, como si no fuera inteligente, pero en cambio muy buena, un montón. Su padre era cojo. Había perdido la pierna en la guerra [...].12" (BOLAÑO, 2009, p. 793)

A história é narrada em 2666, no futuro, o que se comprova pela expressão em pretérito dos acontecimentos evocados. Assim, 2666 bem poderia ser aquele ponto em comum no tempo, ponto que junta e reúne os narradores da história. Dessa forma, podemos observar que, ao se tratar de uma ficção cifrada desde a perspectiva de um futuro tão remoto e distante

8 "A primeira vez que Jean-Claude Pelletier leu Benno von Archimboldi foi no Natal de 1980, em Paris, onde fazia estudos universitários de literatura alemã, aos dezenove anos de idade." (Esta tradução da citação de 2666, e todas as seguintes desse livro específico de Roberto Bolaño foram tomadas da edição em português, realizada pela Companhia das Letras, em 2010. O tradutor é Eduardo Brandão.)

9 "Não sei o que vim fazer em Santa Teresa, se disse Amalfitano ao cabo de uma semana vivendo na cidade. Não sabe? Não sabe mesmo?, perguntou-se. Verdadeiramente não sei, disse a si mesmo, e não pôde ser mais eloquente."

10 "Quando tudo começou?, pensou. Em que momento afundei? (...) queria mesmo sair? Queria mesmo deixar tudo para trás? E também pensou: a dor não importa. E também: talvez tudo tenha começado com a morte da minha mãe."

11 "A morta apareceu num terreno baldio na colônia Las Flores. Vestia camiseta branca de manga comprida e saia amarela até os joelhos, um número maior."

12 "Sua mãe era caolha. Tinha o cabelo muito louro e era caolha. Seu olho bom era aprazível, como se não fosse inteligente, mas, isso sim, muito boa, boa à beça. Seu pai era perneta. Havia perdido a perna na guerra." 
no tempo, o que se apresenta ao leitor em 2666 é um texto que o ultrapassa em termos temporais e que o contém no tempo como sujeito histórico.

Por último, se revisarmos as obras anteriores a 2666, a cifra 2666 não se mostra nova. Precisamente no romance Amuleto (1999), põe-se na boca da protagonista Auxilio Lacouture a seguinte descrição da Avenida Guerrero na Cidade do México:

[...] la Guerrero, a esa hora, se parece sobre todas las cosas a un cementerio, pero no a un cementerio de 1974 , ni a un cementerio de 1968 , ni a un cementerio de 1975 , sino a un cementerio de 2666 , un cementerio olvidado debajo de un párpado muerto o nonato, las acuosidades de un ojo que por querer olvidar algo ha terminado por olvidarlo todo (BOLAÑO, 1999, p. 76$77)^{13}$.

Nessa citação, a cifra 2666 significa também um ponto no tempo, a data de um futuro remoto, que submerge tanto o nosso presente (o dos leitores, o da escrita) quanto os seus protagonistas no nada do esquecimento absoluto e da morte.

O seguinte paratexto, especialmente significativo, é a citação de Charles Baudelaire no começo de 2666. Trata-se de uma tradução do poema de Baudelaire Le Voyage, incluído originalmente em Les fleurs du mal (1857). A epígrafe diz: "Un oasis de horror en medio de un desierto de aburrimiento" 14 . Observando essa cita de Baudelaire no interior de outros textos que rodeiam o romance, é possível pensar que ela tem o objetivo de levar o leitor a lê-la de uma determinada maneira. Se considerarmos o importante lugar que Baudelaire e outros poetas franceses de vanguarda

13 “[...] a Guerrero, a essa hora, se parece mais que tudo com um cemitério, mas não com um cemitério de 1974, nem com um cemitério de 1968, nem com um cemitério de 1975, mas com um cemitério do ano de 2666, um cemitério escondido debaixo de uma pálpebra morta ou ainda não nascida, as aquosidades desapaixonadas de um olho que, por querer esquecer algo, acabou esquecendo tudo." 
(como Rimbaud ou Mallarmé) ocupam na biblioteca e na obra de Bolaño, descobrimos que essa mesma cita já tinha sido tematizada em outros textos.

Em "Literatura + Enfermedad = Enfermedad", na qual o narrador se refere à relação entre a escrita, o escritor e a doença, e ao fato de escrever em uma situação extrema de doença - ou melhor, escrever em uma situação limítrofe entre a vida e a morte; ali aparece a já mencionada citação de Baudelaire para propor um diagnóstico do homem e do mundo modernos:

Y con ese verso, la verdad, ya tenemos más que suficiente. En medio de un desierto de aburrimiento, un oasis de horror. No hay diagnóstico más lúcido para expresar la enfermedad del hombre moderno. Para salir del aburrimiento, para escapar del punto muerto, lo único que tenemos a mano, y no tan a mano, en esto también hay que esforzarse, es el horror, es decir el mal. O vivimos como zombis, como esclavos alimentados con soma, o nos convertimos en esclavizadores, en seres malignos [...] Un oasis siempre es un oasis, sobre todo si uno sale de un desierto de aburrimiento. ${ }^{15}$ (BOLAÑO, 1997, p. 528)

Com a citação, apresenta-se uma concepção muito específica do homem moderno, a qual não somente trata da naturalização do mal e da doença como também afirma que o mal é um aspecto constitutivo e uma necessidade humana, frente ao spleen, que não é mais do que a realidade. Essa concepção parece constituir uma das colunas fundamentais, para não dizer "a" temática central, que estrutura o romance 2666.

Nesse sentido, a cita de Baudelaire poderia ser pensada como um primeiro sinal do autor aos leitores do seu romance, colocando em

15 "E com esse verso, na verdade, basta e sobra. Em meio a um deserto de tédio, um oásis de horror. Para sair do tédio, para escapar do ponto morto, só o que temos na mão, e nem tanto, porque para isso também precisamos nos esforçar, é o horror, quer dizer, o mal. Ou vivemos como zumbis, como escravos, alimentados com soma, ou nos transformamos em escravizadores, em seres malignos [...]. Um oásis é sempre um oásis, especialmente se a gente está saindo de um deserto de tédio." (tradução a.b.) 
evidência, desde o primeiro momento, um diagnóstico, que é uma afirmação, sobre a relação com e entre a humanidade, a existência, o mal, o horror e, no interior deste panorama, o papel da literatura como forma de busca ou construção de sentido.

Existem em 2666, por outro lado, diversas referências de ordem intertextual, relacionadas com obras anteriores do próprio Bolaño. Uma delas é o deserto de Sonora, onde se dava início à fuga de Arturo Belano, Ulises Lima, Lupe e Madero no final de Los detectives Salvajes (1998). En 2666 escolhe-se outra vez esse espaço (a cidade de Santa Teresa, o deserto do norte do México, na zona fronteiriça com os Estados Unidos) como centro articulador da história. Na nutrida bibliografia sobre 2666, o artigo de Cathy Fourez, de 2006, foi o primeiro a destacar de modo pertinente esse ponto.16 Mas se em Los detectives Salvajes o deserto de Sonora é esse espaço aberto para a busca de Cesarea Tinarejo e o ponto de fuga final dos personagens, em 2666 volta a ser o centro de uma procura múltipla, sendo também a busca do horror e do mal.

Outra referência a textos anteriores do autor está relacionada com a identidade do narrador de 2666, Arturo Belano, cuja voz, protagonismo e importância não são alheias a nenhum leitor conhecedor das obras anteriores de Bolaño: Estrella distante; Amuleto; Los detectives Salvajes. (Este é um ponto que os próprios editores ressaltam na "Nota a la primera edición”, BOLAÑO, 2009, p. 1125).

\section{As partes do romance}

Dilucidados os "rastros" do autor nos paratextos, propomos agora uma análise das diferentes partes do romance com base no questionamento em torno de três problemáticas que definem 2666: a busca; a representação

16 Ver Cathy Fourez, 2006. 
sem mediações do horror; e a autoria. Essas temáticas estruturam a obra e possivelmente resulta delas, em parte, que em 2666 haja um novo paradigma na literatura de língua espanhola.

As três primeiras partes de 2666 parecem assumir diretamente a temática da busca: os motivos que a desencadeiam; os meios com os quais conta para ser levada a cabo; o lugar onde começa; o lugar onde se chega; e seus resultados. Vale dizer que, no caso dessa temática, não estamos falando de uma problemática mais, mas sim de um dos principais temas do gênero romance e que, no interior do contexto literário latino-americano, o romance como busca e a busca do romance são topoi da segunda metade do século XX. Dessa forma, ao trabalhar no texto uma das principais temáticas do romance como gênero, Bolaño parece iniciar seu próprio “jogo" em um terreno, em maior ou menor medida, familiar ao leitor e já percorrido pelo romance latino-americano. A questão mais importante a analisar seria, então, o que faz o autor dessa questão e como essa temática é trabalhada em 2666.

Encontramos no romance alinhamentos recorrentes no que se refere à "busca" dos personagens em cada "parte" em questão. É isso que torna possível uma leitura das três primeiras partes do romance nessa perspectiva. No que se refere à história, vemos, em primeiro lugar, que tanto em "A parte dos críticos" como em "A parte de Amalfitano" e "A parte de Fate" há um confronto direto relacionado com a busca, objeto de reflexão entre os personagens. Observando outra vez os três começos, correspondentes aos inícios das três primeiras "partes" do romance e já citados na análise dos paratextos, podemos observar no relato uma resposta direta a essa problemática. "A parte dos críticos" trata de como o francês Pelletier, o espanhol Espinoza, o italiano Morini e a inglesa Norton topam com a obra de Archimboldi e se lançam à sua procura, começando com o velho continente para terminar aterrissando no deserto de Sonora. "A parte de Amalfitano" trata dos motivos que levaram o chileno Amalfitano a sair da 
Espanha com sua família e dirigir-se a Santa Teresa. Por último, "A parte de Fate" tem, como ponto de partida, o questionamento sobre os motivos que levam o jornalista Quincy Williams (conhecido pelo pseudônimo de Oscar Fate) a prolongar sua estadia em Santa Teresa, submergido no mistério dos crimes contra mulheres que vêm acontecendo naquela cidade.

Um segundo aspecto em comum é o fato de que, para além das diferentes trajetórias, procedências e motivos particulares de cada personagem, Santa Teresa se converte no espaço comum da busca. Quais são as características desse espaço escolhido pelo narrador para plasmar as histórias narradas? O que nos dizem sobre a cidade é que está localizada no deserto de Sonora, na fronteira com os Estados Unidos; que ali há uma universidade; que muitas das mulheres que moram ali trabalham nas montadoras e muitos dos homens, no transporte de indocumentados atravessando a fronteira. Santa Teresa é, portanto, uma cidade de passagem, não só para o tráfico de bens, o narcotráfico e o contrabando, mas também para migrantes de todo o continente que tentavam cruzar a fronteira entre o México e os Estados Unidos. E talvez o mais importante: essa cidade foi se transformando, desde o ano de 1993, em um cenário de horror pela generalização de crimes contra mulheres, que ficam todos, e sempre, sem esclarecer.

- ¿De qué demonios estás hablando? -le preguntó Fate a Chucho Flores mientras desayunaban en un bar cercano al pabellón Arena Norte.

- De los asesinatos de mujeres [...] Florecen -dijo-. Cada cierto tiempo florecen y vuelven a ser noticia y los periodistas hablan de ellos. La gente también vuelve a hablar de ellos y la historia crece como una bola de nieve hasta que sale el sol y la pinche bola de nieve se derrite y todos se olvidan y vuelven al trabajo. [...]

- Ésta es una ciudad completa, redonda-dijo Chucho Flores-. Tenemos de todo: Fábricas, maquiladoras, un índice de desempleo muy bajo, uno de los más bajos 
de México, un cártel de cocaína, un flujo constante de trabajadores que vienen de otros pueblos, emigrantes centroamericanos, un proyecto urbanístico incapaz de soportar la tasa de crecimiento demográfico, tenemos dinero y también hay mucha pobreza, tenemos imaginación y burocracia, violencia y ganas de trabajar en paz 17. (BOLAÑO, 2009, p. 362).

O confronto dos personagens das três primeiras partes de 2666 com esses crimes constitui o terceiro ponto em comum, no interior das respectivas buscas. Os críticos, no meio do seu rastreio do paradeiro de Archimboldo, terão conhecimento dos crimes contra as mulheres. $\mathrm{O}$ curioso é que essa informação não mudará nem afetará em nada o seu objetivo, transformando o grave problema dos assassinatos em um dado anedótico mais:

Espinoza recordó entonces que durante la noche pasada uno de los muchachos le había contado la historia de las mujeres asesinadas. Sólo recordaba que el muchacho había dicho que eran más de doscientas y que tuvo que repetirlo dos o tres veces, pues ni Pelletier ni él daban crédito a lo que oían 18 . (BOLAÑO, 2009, p. 181)

Coisa similar acontece em "A parte de Amalfitano", na qual esse personagem está mais concentrado em decifrar o significado dos seus

17 “- De que diabos estavam falando? - Fate perguntou a Chucho Flores enquanto lanchavam num bar próximo do ginásio Arena do Norte. - Dos assassinatos de mulheres - respondeu Chucho Flores com desânimo. Florescem - disse. - A cada certo tempo florescem e voltam a ser notícia, e os jornalistas falam deles. As pessoas também tornam a falar deles e a história cresce como uma bola de neve até sair o sol, aí a merda da bola se derrete, todos se esquecem e voltam ao trabalho."

$[\ldots]$

“- Esta cidade é uma cidade completa, redonda - disse Chucho Flores. - Temos de tudo. Fábricas, maquiladoras, um índice de desemprego muito baixo, um dos mais baixos do México, um cartel de cocaína, um fluxo constante de trabalhadores que vêm de outras cidades, emigrantes centro-americanos, um projeto urbanístico incapaz de suportar a taxa de crescimento demográfico, temos dinheiro e também há muita pobreza, temos imaginação e burocracia, violência e vontade de trabalhar em paz."

18 "Espinoza se lembrou então que na noite anterior um dos rapazes havia contado para eles a história das mulheres assassinadas. Só lembrava que o rapaz tinha dito que eram mais de duzentas e que teve de repetir duas ou três vezes, porque nem ele nem Pelletier davam crédito ao que ouviam." 
sonhos e visões, em desvelar o mistério que pressente iminente, do que em observar e se preocupar com o que acontece em Santa Teresa:

Esa noche, sin embargo, después de cenar y de ver las noticias en la tele y de hablar por teléfono con la profesora Silvia Pérez, que estaba indignada por la forma en que la policía del estado de Sonora y la policía local de Santa Teresa estaba llevando la investigación de los crímenes, Amalfitano encontró en la mesa de su escritorio tres dibujos más 19. (BOLAÑO, 2009, p. 248)

O caso de Oscar Fate é diferente. Chegando em Santa Teresa para cobrir uma importante luta de boxe, ao saber dos crimes, irá prolongando sua estadia na tentativa de investigar os casos:

Mientras conducía rumbo al Sonora Resort, desde donde pensaba revisar su correo electrónico, a Fate se le ocurrió que mucho más interesante que la pelea Pickett-Fernández era escribir un reportaje sobre las mujeres asesinadas. Así se lo escribió a su jefe de sección. Le pidió quedarse una semana más en la ciudad y que le enviaran un fotógrafo20. (BOLAÑO, 2009, p. 364)

Dessa maneira, podemos observar como em 2666 se constrói um cenário da busca determinado por rasgos característicos da globalização na América Latina: a imigração, a impunidade, a corrupção, a pobreza, o

19 "Naquela noite, porém, depois de jantar e ver as notícias na tevê e falar por telefone com a professora Silvia Pérez, que estava indignada com a forma como a polícia do estado de Sonora e a polícia local de Santa Teresa estavam conduzindo a investigação dos crimes, Amalfitano encontrou na mesa do seu escritório mais três desenhos."

20 "Enquanto dirigia rumo ao Sonora Resort, onde pensava conferir suas mensagens eletrônicas, ocorreu a Fate que muito mais interessante do que a luta Pickett-Fernández era fazer uma reportagem sobre as mulheres assassinadas. Escreveu dizendo isso a seu chefe de seção. Pediu para ficar mais uma semana na cidade e que mandassem um fotógrafo." 
narcotráfico e as montadoras, entre outros. Nesse espaço desenvolve-se a história de cada personagem. Soma-se a isso o confronto dos personagens e seus objetivos com o horror dos fatos violentos e seu não esclarecimento, frente ao qual aqueles (exceto Fate) reagem com indiferença, sem chegar a duvidar por um momento sequer que neles, no esclarecimento deles, possa talvez estar a chave da sua busca.

\section{Um oásis de horror no limite de qualquer representação possível}

Passados os três primeiros capítulos, no quarto, "A parte dos crimes", produz-se uma ruptura significativa no interior do romance, em vários níveis, sendo essa ruptura a que permite separar e isolar dito capítulo do resto deles. Dada a magnitude do interior da história e o conteúdo do capítulo, "A parte dos crimes" se constitui, tanto na forma quanto no conteúdo, como um verdadeiro "oásis de horror" no interior do mapa traçado em 2666, que aparece respondendo à citação inicial do romance. Os elementos que definem os diferentes níveis de ruptura nesse capítulo, esse oásis de horror no meio do deserto, no meio da monotonia do relato, podem ser esquematizados assim:

No romance, a mudança consiste na ausência de um capítulo que continue a história traçada nas três primeiras partes. Sob uma forma aparentemente comum às partes anteriores (um título que começa com "A parte de", um capítulo no interior do romance), serão os crimes, pelo contrário, os que terão o protagonismo absoluto. Se nas partes anteriores esses apareciam nas margens, agora conquistam o lugar principal da história, provocando, assim, o leitor a confrontar-se com essa realidade, mais do que os personagens. Como é possível observar nas primeiras orações, a mudança produz-se bruscamente e sem intermediação alguma através do relato, provocando um confronto mais que direto: 
La muerta apareció en un pequeño descampado en la colonia Las Flores. Vestía camiseta blanca de manga larga y falda de color amarillo hasta las rodillas, de talla superior. Unos niños que jugaban en el descampado la encontraron y dieron aviso a sus padres $^{21}$ (BOLAÑO, 2009, p. 443).

Outro importante indício de ruptura são as transformações sofridas nesta parte pelo discurso mesmo do romance. Até a terceira parte, o relato compartilhava de uma estrutura em comum, no que se refere à quantidade de páginas, ao estilo narrativo das respectivas histórias, caracterizado pela presença de diálogos, monólogo interior, relato encadeado dos fatos e voz narrativa. "A parte dos crimes" apresenta uma mudança radical nessa estrutura. Em primeiro lugar, a quantidade de páginas é significativamente maior do que a das outras "partes"; por outro lado, o discurso passa de relato romanceado a registro policial, tomando a forma de uma pesquisa forense:

Cinco días después, antes de que acabara el mes de enero, fue estrangulada Luisa Celina Vázquez. Tenía dieciséis años, de complexión robusta, piel blanca, y estaba embarazada de cinco meses. El hombre con el que vivía y el amigo de éste se dedicaba a pequeños hurtos en tiendas y almacenes de electrodomésticos. La policía acudió alertada por un aviso de los vecinos del edificio, sitio en la Avenida Rubén Darío, en la colonia Marcera. Tras forzar la puerta encontraron a Luisa Celina estrangulada con un cable de televisión (BOLAÑO, 2009, p. 445). ${ }^{22}$

21 "A morta apareceu num terreno baldio na colônia Las Flores. Vestia camiseta branca de manga comprida e saia amarela até os joelhos, um número maior. Uns garotos que brincavam no terreno a encontraram e avisaram os pais."

22 "Cinco dias depois, antes que o mês de janeiro acabasse, foi estrangulada Luisa Celina Vázquez. Tinha dezesseis anos, de compleição robusta, pele branca e estava grávida de cinco meses. O homem com o qual vivia e o amigo deste se dedicavam a pequenos furtos em lojas e revendedoras de eletrodomésticos. A polícia apareceu, alertada por um aviso dos moradores do edifício, situado na avenida Rubén Darío, na colônia Mancera. Depois de forçar a porta encontraram Luisa Celina estrangulada com um fio de televisão." 
É chamativa aqui a minúcia da descrição, pois nem a cronologia está descuidada, nem as características físicas da vítima, seu meio social ou a forma como a polícia se depara com o corpo. Essa classe de descrições são as mais plasmadas em "A parte dos crimes", acoplando-se uma após a outra, como acontece em qualquer arquivo judicial. Desta forma, o relato torna-se uma abordagem sistemática de um enorme número de crimes, o que converte o leitor em agente da polícia, habituado a tratar com esse tipo de "expedientes policiais":

La mujer se llamaba Isabel Cansino, más conocida por Elizabeth, y se dedicaba a la prostitución. Los golpes recibidos le habían destrozado el brazo. La policía achacó el crimen a uno o varios clientes descontentos. Vivía en la colonia San Damián, bastante más al sur de donde fue encontrada, y no se le conocía compañero fijo [...].

Al mes siguiente, en mayo, se encontró a una mujer muerta en un basurero situado entre la colonia Las Flores y el parque industrial General Sepúlveda. En el polígono se levantaban los edificios de cuatro maquiladoras dedicadas al ensamblaje de piezas de electrodomésticos (BOLAÑO, 2009, p. 448-449). ${ }^{23}$

Quais são as consequências dessa ruptura discursiva na recepção do leitor? Parece que, através do tipo de discurso plasmado nesse capítulo, os alcances da representação do crime escapam do efeito esperável e habitual de horrorizar e paralisar o leitor, atitude que em última instância contribui para a autoproteção e a autoconservação do mesmo em sua integridade. Mais ainda, no relato de "A parte dos crimes", é possível transpor esses

23 "A mulher se chamava Isabel Cansino, mais conhecida como Elizabeth, e se dedicava à prostituição. Os golpes recebidos haviam destroçado seu baço. A polícia atribuiu o crime a um ou vários clientes descontentes. Morava na colônia San Damián, bem mais ao sul de onde foi encontrada, e ao que se sabia não tinha companheiro fixo $[\ldots]$.

No mês seguinte, em maio, foi encontrada uma mulher morta num lixão situado entre a colônia Las Flores e o parque industrial General Sepúlveda. No parque se levantavam os edifícios de quatro maquiladoras dedicadas à montagem de peças de eletrodomésticos." 
marcos tradicionais, fazendo com que o leitor se habitue a esse confronto com o mal a partir do enorme número de casos exibidos, naturalizando-o e terminando, assim, por anulá-lo. No final, o efeito conseguido é que o próprio leitor se torna parte da mesma banalidade do mal e do horror representados em 2666.

A pergunta é se desse modo, nesse capítulo, Bolaño põe em marcha uma experimentação extrema com o romance como gênero e com a literatura em geral, com seus alcances e formas, ao enfrentá-la, em tanto representação, com as manifestações mais perversas do horror, com a naturalização desse horror, conseguindo aproximá-la dos limites mais extremos.

\section{No final do caminho, dois rumos mascarados e enganosos: a}

\section{autoria e a literatura}

$\mathrm{Na}$ última parte do romance, "A parte de Archimboldi", relatase a particular história de Hans Reiter, desde o seu nascimento em uma pequena aldeia prussiana, passando por sua reinvenção como "Benno von Archimboldi", até chegar a sua viagem a Santa Teresa para reencontrar-se com seu sobrinho encarcerado, Klaus Haas. São muitos os indícios que levam a pensar a figura de Archimboldi como uma alegoria que bem poderia estar encarnando a literatura: sua busca permanente, sua capacidade de autocriar-se e reinventar-se constantemente.

Em primeiro lugar, a figura de Hans Reiter está em constante mutação, transpassando qualquer fronteira ou molde preexistente desde o primeiro instante do seu aparecimento. Nascido de uma mãe caolha e de um pai coxo no período de entreguerras, os primeiros anos de vida desse menino de aparência esquisita estão determinados pela sua curiosa paixão e fascínio pelo mundo aquático: 
No parecía un niño sino un alga. Canetti y creo que también Borges, dos hombres tan distintos, dijeron que así como el mar era el símbolo o el espejo de los ingleses, el bosque era la metáfora donde vivían los alemanes. De esta regla quedó fuera Hans Reiter desde el momento de nacer. No le gustaba la tierra y menos aún los bosques. Tampoco le gustaba el mar o lo que el común de los mortales llama mar, y que en realidad sólo es la superficie del mar, las olas erizadas por el viento que poco a poco se han ido convirtiendo en la metáfora de la derrota y la locura. Lo que le gustaba era el fondo del mar, esa otra tierra llena de planicies que no eran planicies y valles que no eran valles y precipicios que no eran precipicios (idem, 797). ${ }^{24}$

O ponto de partida da existência da figura de Reiter está marcado, assim, pelo seu posicionamento no outro lado, pelo seu não-cabimento no interior de qualquer molde concebido, pelo seu modo de olhar o mundo como se fosse um planeta estranho, pois Reiter "caminha como um mergulhador" (BOLAÑO, 2009, p. 803). Sobretudo, tal como mostra esse fragmento, sua figura também não se deixa enquadrar nas categorias literárias habituais, impedindo que possa se refletir em qualquer um dos espelhos usuais.

Em segundo lugar, talvez como consequência dessa predeterminação à ruptura constante com as formas pré-existentes, esse personagem é objeto e sujeito de uma auto-invenção constante. Se o jovem Reiter se define no começo como um mergulhador apaixonado e explorador do mundo aquático, logo passará a fazer parte do exército alemão durante a II Guerra

24 "Não parecia um menino, mas uma alga. Canetti e creio que também Borges, dois homens tão diferentes, disseram que assim como o mar era o símbolo ou o espelho dos ingleses, o bosque era a metáfora onde viviam os alemães. Dessa regra Hans Reiter ficou de fora desde o momento que nasceu. Não gostava da terra e ainda menos dos bosques. Também não gostava do mar ou o que o comum dos mortais chama de mar e que na realidade é só a superfície do mar, as ondas eriçadas pelo vento que pouco apouco foram se convertendo na metáfora da derrota e da loucura. O que ele gostava era do fundo do mar, essa outra terra, cheia de planícies que não eram planícies e vales que não eram vales e precipícios que não eram precipícios." 
Mundial. Nele, não terá o desempenho característico de um soldado (não mata nenhum inimigo), e depois permanecerá muito tempo refugiado no esconderijo que tinha sido do russo judeu Ansky, imerso na leitura dos seus cadernos. Desse último tomará muitos elementos para sua próxima autorreconstrução, talvez a mais importante de todas; a do escritor Benno von Archimboldi.

En el cuaderno de Ansky aparece, y es la primera vez que Reiter lee algo sobre él, mucho antes de ver una pintura suya, el pintor italiano Archimboldo [...]. Cuando estoy triste o aburrido, dice Ansky en el cuaderno, aunque es difícil imaginar a Ansky aburrido, ocupado en huir las veinticuatro horas del día, pienso en Giuseppe Archimboldo y la tristeza y el tedio se evaporan como en una mañana de primavera $[\ldots] .{ }^{25}$ (BOLAÑO, 2009, p. 911).

A autoinvenção de Reiter como o escritor Archimboldi, ligada na história ao seu desejo de ocultar a identidade pelo crime cometido em um campo de prisioneiros estadunidense, põe em relevo questões mais complexas sobre o valor intrínseco da identidade e, com isso, da autoria do escritor. Esse personagem representa em 2666 um questionamento profundo desses dois elementos. Neste sentido, a referência ao pintor Giuseppe Archimboldo não é casual: este compunha retratos humanos a partir de "objetos", tais como frutas, animais, reafirmando, assim, o caráter passível de construção e desconstrução do homem e da percepção de si mesmo com pinturas que, no século XVI, questionariam o ideal renascentista de beleza humana.

Além disso, o momento da "metamorfose” de Reiter em Archimboldi

25 "No caderno de Ansky aparece, e é a primeira vez que Reiter lê algo sobre ele, muito antes de ver uma pintura sua, o pintor italiano Arcimboldo [...]. Quando estou triste ou entediado, diz Ansky no caderno, mas é difícil imaginar Ansky entediado, ocupado em fugir vinte e quatro horas por dia, penso em Giuseppe Arcimboldo e a tristeza e o tédio se evaporam como numa manhã de primavera." 
acontece nos escritórios da editora de "Bubis". De onde sai semelhante sobrenome para estampar-se nas páginas de 2666? É muito provável que se trate de um jogo alusivo ao nome de Ignatz Bubis, sobrevivente de um campo de concentração durante o Holocausto e presidente do Conselho Judeu na Alemanha. Durante o primeiro encontro entre ambos, o tema da verdadeira identidade de Archimboldi, da sua "pureza", converte-se em gatilho de um diagnóstico mais amplo da história alemã e europeia do século XX:

- Mi nombre es Benno von Archimboldi, señor dijo Reiter-, y si usted cree que estoy bromeando lo mejor será que me vaya.

Durante unos instantes los dos permanecieron en silencio. [...] Los ojos de Archimboldi eran azules $\mathrm{y}$ al viejo le parecieron los ojos de un joven poeta, unos ojos cansados, maltratados, enrojecidos, pero jóvenes y en cierto sentido puros, aunque el viejo hacía mucho que había dejado de creer en la pureza. - Este país - le dijo a Reiter, que aquella tarde se convirtió, tal vez, en Archimboldi - ha intentado arrojar al abismo a varios países en nombre de la pureza y de la voluntad. Para mí, como usted comprenderá, la pureza y la voluntad son puro mariconeo. Gracias a la pureza y la voluntad nos hemos convertido todos, entiéndalo bien, todos, todos, en un país de cobardes y de matones, que al fin y al cabo son lo mismo (BOLAÑO, 2009, p. 981). ${ }^{26}$

Por último, a figura de Reiter, como depois a de Archimboldi,

26 “- Meu nome é Benno von Archimboldi, senhor — disse Reiter —, e se o senhor acha que estou brincando o melhor é que eu me vá.

Por uns instantes ambos permaneceram em silêncio. [...] Os olhos de Archimboldi eram azuis e pareceram ao velho olhos de um jovem poeta, olhos cansados, maltratados, avermelhados, mas jovens e em certo sentido puros, se bem que fazia muito que o velho havia deixado de crer na pureza.

- Este país - disse ele a Reiter, que naquela tarde se transformou, talvez, em Archimboldi —, tentou jogar no abismo vários países em nome da pureza e da vontade. Para mim, como o senhor há de compreender, a pureza e a vontade são pura frescura. Graças à pureza e à vontade nos transformamos todos, entenda bem, todos, todos, num país de covardes e brutamontes, o que no fim das contas é a mesma coisa." 
atravessará uma multiplicidade de tempos e espaços que abrangem a totalidade do século XX. Partindo do começo da I Guerra Mundial, passando pelo mundo nas entreguerras e pelo mundo da II Guerra na Alemanha, na Europa do Leste e na União Soviética, continuando no mundo alemão do pós-guerra até chegar ao tempo mais contemporâneo em diferentes países e cidades europeias, Archimboldi se desloca de modo constante, fugindo de todo tipo de enquadramento, transpassando simultaneamente todas as fronteiras e espaços possíveis. No final, é-nos antecipado ainda seu próximo destino: a cidade mexicana de Santa Teresa.

Pode ver-se, assim, como nesse capítulo a própria literatura, o gênero do romance, encarnados na literatura fantasmagórica de Archimboldi, vai atravessando todos os espaços possíveis, em todas as dimensões (tempo, espaço, horror e "normalidade"), e, assim, vai reinventando-se constantemente, em uma tentativa de saltar as fronteiras do existente e do concebível.

Cabe concluir que 2666 representa um projeto de busca múltipla ao redor dos limites próprios do romance e da literatura, até o ponto em que o gênero se questiona, nas suas formas e elementos mais característicos. O mérito de 2666 parece residir em fazer retroceder os limites da representação e através dessa ficção penetra-se em terrenos não transitados na literatura hispano-americana e pratica-se, na especial continuidade dos seus escritos, o jogo da fractalidade, para usar o termo matemático de Benoît Mandelbrot.

O fim da busca em 2666 como discurso e como história fica em aberto e potencializado a possibilidades infinitas: fica nas mãos do leitor, na medida em que esse o deseje. Esse último aspecto permite arriscar uma hipótese: provavelmente Bolaño não esteja fazendo outra coisa em 2666 do que, precisamente, propor a busca e sobre tudo, a busca através da literatura, como um exercício complexo, interminável e de ultrapassagem constante. A questão é como sair do círculo maligno de uma existência - a 
contemporânea - povoada de desertos de abulia e oásis de horror. A busca, longe de ter terminado com a pós-modernidade, apenas começa com ela, tornando-se muito mais complexa, mais necessária e desafiadora do que nunca.

\section{Referências}

BOLAÑO, Roberto. Literatura + enfermedad = enfermedad. In: Cuentos: Putas asesinas. Llamadas telefónicas. El gaucho insufrible. Barcelona: Anagrama, 1997, 515-533.

Amuleto. Barcelona: Anagrama, 1999.

2666. Barcelona: Anagrama, 2009 (10 edición).

FOUREZ, C. Entre trasfiguración y transgresión. El esquema espacial de Santa Teresa en la novela de Roberto Bolaño, 2666. In: Debate feminista, XVI (2006) 33, 21-46.

MANDELBROT, B. The Fractal Geometry of Nature. San Francisco: W.H. Freeman and Company, 1983.

MANZONI, C., GRAS, D. e Brodsky, R. (eds.). Jornadas homenaje a Roberto Bolaño (1953-2003). Barcelona: ICCI Casa Amèrica a Catalunya, 2005, 51-73.

NÚÑEZ, G. "La 'bolañomanía’ llega a la República Checa”. In: Czech Radio, 03.10.2009. Disponível na internet em: https://espanol.radio.cz/la-bolanomania-llega-a-la-republica-checa-8580529 Acesso em 14 de agosto de 2012.

RODRÍGUEZ R., M. Bolañomanía sin tildes. In: El País, 09.12.2008. Disponível na internet, em: https://elpais.com/diario/2008/12/10/cultura/1228863604_850215.html Acesso: 10 ag. 2012. 


\section{WELSCH, W. Unsere postmoderne Moderne. Weinheim: VCH, Acta Hu- maniora, 1987, 77-188.}

\section{El efecto 2666 y el modelo fractal}

Resumen: El artículo parte de un examen de la repercusión, éxito y circunstancias especiales de la escritura y publicación internacional de la novela, para especificar lo que llama: El efecto 2666. Procede así para centrarse en el análisis de los paratextos e incipit (párrafos iniciales) de las diferentes partes de 2666, sobre el horizonte de lo fractal y la fractalidad según Benoit Mandelbrot y Wolfgang Welsch, y de las temáticas de la búsqueda, la representación sin mediaciones del horror y la autoría. Con esta última se toca el intento de superación de los límites de la novela como género que hay en 2666, vinculado con la cuestión de la Global Novel. Palabras clave: Roberto Bolaño. 2666. Fractal-fractalidad. Autoría. Global Novel.

\section{The 2666 efect and the fractal model}

Abstract: The present article emanates from an examination of the repercussion, success and special circumstances of the writing and international publication of the novel 2666, to specify what is called: the 2666 Effect. It proceeds that way in order to focus on the analysis of the paratexts and incipit (initial paragraphs) of the different parts of 2666, on the horizon of the fractal and fractality, according to Benoit Mandelbrot and Wolfgang Welsch, and the subject matter: the search for, the representation without mediations of horror and authorship. The latter touches the intent of surpassing the limits of the novel as genre present in 2666, linked with the question of the Global Novel. Keywords: Roberto Bolaño. 2666. Fractal-fractality. Authorship. Global Novel.

\section{Recebido em: 30/08/2021}

Aceito em: 17/09/2021 